\title{
Persuasive Learning Strategies for Transforming Engineering Education
}

\author{
Govil Alok $^{1}$, Pillalamarri Saipriya ${ }^{2}$, N. Prabhanjan ${ }^{3}$ \\ ${ }^{1}$ Department of Civil Engineering, S R Engineering College, Warangal, Telangana, India \\ ${ }^{2}$ Department of Civil Engineering, S R Engineering College, Warangal, Telangana, India \\ ${ }^{3}$ Department of Civil Engineering, S R Engineering College, Warangal, Telangana, India \\ 1alok_govil@srecwarangal.ac.in \\ ${ }^{2}$ pillalamarrisaipriya@gmail.com \\ ${ }^{3}$ prabhanjan_n@srecwarangal.ac.in
}

\begin{abstract}
Education, be it Primary, Secondary, Higher or Engineering, all play their crucial roles in every individual's life. Among these, engineering education has always been in the limelight, which has become important for the young generation to march forward in the competitive world. Ameliorating Engineering education has become highly important since traditional and conventional methodologies of teaching and learning have curbed the creative aspects of learners. Though having a diverse atmosphere in the Colleges, the common ground wherein people interact is less. In order to infuse collaborative learning, spaces like Makers Space, Tinkering Labs, Design studios and many more are being built where individuals irrespective of discipline actively participate and work on their projects, thereby bringing a multi-disciplinary approach. Many Institutions are striving to enforce usage of technologies and various tools in their education system, yet thriving to achieve success. There is a need to understand the importance of technology, which drives innovative abilities among learners and educators. It is important to have strategic planning rather than statistical planning by eliminating the bureaucracy.
\end{abstract}

Keywords: Creativity, Innovation, Technology, Engineering Education, Challenges

\begin{abstract}
Govil Alok
Department of Civil Engineering, S R Engineering College, Warangal, Telangana, India alok_govil@srecwarangal.ac.in

\section{Introduction}

Engineering is integral to lean towards Sustainable Development for a better and organized society. The freshmen who undertake engineering courses are the future in building a nation, who is to be provided with the best learning in their professional courses. They have to be deeprooted with foundations to encompass practical and theoretical knowledge in Industrial and Corporate sectors to enlighten them with the needs of the various Communities and Societies.
\end{abstract}

Over many decades there has been a paradigm shift in the field of education where the most significant changes were observed in engineering education. Previously Engineering included only a few broad departments like Military and Civil. As it became difficult to master all the skills, these Departments were further categorized into Electrical, Electronics, Computer science, Aeronautics, Chemical, etc., These were introduced with a motive to increase the efficiency of students in learning higher skills \& techniques in their four Year Curriculum. It also helped employers to acquire productive employees to meet their specific needs and advanced demands in the world of technological advancement and competition. Theoretical understanding, creativity and innovation, teamwork, technical breadth, and business skills are key elements to be addressed [4]. It is indeed necessary to provide elucidated teaching and learning practices that encompass a curriculum with effective assessments and activities, which leads the students to acquire skills in particular with respect to the present scenario. An Industry-Institute collaborative design shall be implemented which shall boost both institutes and industry requirements [5] 


\section{Challenges in Engineering Education}

\section{A. Practical / Industrial Awareness}

Students aren't exposed to examples in real life using engineering principles. Mere classroom and laboratory principles do not provide real time learning. Engineering education needs to focus on real-time learning techniques and have many Industry-Institute Partnerships to excite the students in solving the practical real-world problems. Shadowing industry (?) works should be practiced to understand the techniques and solutions. There is a constant lag between Industry and Institute to interact, understand and to execute. [6]. It is highly important to collaborate with various industries and have a strategic alliance with them in order to attain ideal education and training [13].

\section{B. Communication}

Communication is all about passing the information, thoughts and attitude from one person to another. In the war of engineering (?), communication is considered as a crucial weapon to win. Communication bridges various aspects of engineering and helps students navigate/propel towards their target with meaningful and sensible interactions. As it is well known, communication stands as a vital aspect in the Industry and the corporate world where a person's multilingual abilities are considered to be a salient character [7]. Institutes, though, put their extreme efforts to transform the skills of young engineers, often do not succeed due to various factors like lack of competition, face up with the large audience, end to end interactions, brainstorming and discussions, debates and forums etc., which immensely contribute to the improvement of one's abilities [10].

\section{Employment}

According to the All India Council for Technical Education out of the 8 lakh engineer graduates from all over the technical institutions from the country, about Sixty Percent of the students still remain unemployed. Only a meager number of students, probably lesser than $1-2 \%$ of students participate in internships offered during summer and winter. The quality of the institutions can also be marked by the accreditations of the NBA and shockingly only $15 \%$ of the colleges have it so far. Since the young and bright are the upfront people who shall run the nation in the near future it is very important for our nation to strengthen its foundations of the education system. Many strategies have to be dug out and executed in a meticulous rhythm to buck up the challenges. One such strategy is to put a common entrance based on merit [8].

\section{Ethical Awareness}

Unethical practices have become a contagious tort in our society. Most of us are negligent in many aspects leaning towards unethical lifestyles. It is incumbent on our generation to adhere to ethical ways of living in order to tackle the ill effects of unethical practices by our earlier generations and to lay a path rich of values for generations to come. Mere theoretical education on Professional Ethics and Human Values in the form of a course isn't enough to face the challenges one encounter in the real world, a practical reform is necessary, as done in Gurukuls and other ashrams where there is live exemplary practice. Engineering graduates are to be aware of all of their obligations and duties by virtue. The biggest challenge is how to impart in them the moral conscience of responsibility and accountability in them ensuring strict adherence to the ethical standards. [9].

\section{E. Sustainability}

As we progress forward in the advancement of technology, we leave behind sustainability. Engineering has to be operated in tandem with factors affecting sustainability [16]. As it is well known, how the natural resources are overwhelmingly being exploited, it becomes imperative for everyone to start executing sustainable practice rather than just experimenting and putting on papers. Engineers need to be the upfront executioners of sustainable practices and achieve synergy between sustainable development and technology [10].

\section{F. Methodology}

There is a substantial lack of professional teaching methodology in engineering education. Though there are various Methodologies using various tools and techniques, often institutions are sticking to traditional and conventional teaching methodologies. To bring the flavor of creativity among the learners and spread the innovation culture, it has become necessary for every educator to use various teaching methodologies such as Active Learning Techniques, Collaborative Learning, Role Play, Analogy, Simulations and Presentations, Quiz, Webinars, Video Lectures, Brainstorming, Pain Storming, Problem Solving, Design Process methods and many more. Yet, it is important to know the apt methodology before content delivery.

\section{G. Funding}

Funding has been one of the impounding factors in Engineering Education. It has been observed at various stages of engineering education that, creativity and innovation have been hindered due to insufficient funding depriving people to showcase their effectively. Today, education is considered as a business and not a non-profit offering and this attitude in administration of institutes has led to non-cultivation of a prudent holistic educational system. Also, many times, it is out of proportionality for plenty to have effective education, since, the fee encumbered varies widely upon various factors, especially in Private Sector.

\section{H. General Awareness}

Students nowadays stay blindfolded. They simply don't understand the difference between westernization and modernization. The cognitive aspect of education has to be improved by making them aware. The world demands people who are flexible, versatile and can take up a multitude of tasks effectively. Their diversity in work and range of expertise brings opportunities. In order to bring such 
knowledge, a huge awareness for constant exploration of General studies along with their specific domains is necessary. One needs to explore constantly time to time, in order to compete well, as the present world rate evolving in technology is higher than previous [11].

\section{Curriculum}

It's a fact that our education system is a colonial education system. But if we need our young engineering aspirants to face the critical and technology demanding resilience, it's necessary they get adequate exposure to such skills. We need to organically develop our curriculum upon recent demands of the market. We must integrate curriculum to develop a concept-oriented approach over problem-solving approach. Prescribing and motivating young people to learn designing and innovating thinking is necessary. Appropriate exploration of their respective engineering domain should be provided, naturally [12]. Teaching the design process, developing assessments, balancing technical and academic subjects has become a great challenge. Reorientation of curriculum towards the student-centeredness has to bring the paradigm shift [14].

\section{Creativity and Innovation}

Often in many conversations, we have today; we hear the word creativity and innovation. In common, both of these terms are generally considered to be alike which they aren't.

Creativity can be put as novel ideas that are generally useful. It is more inclined towards pitching ideas, trying new things, taking risks. Creativity is conceiving something new or original.

Innovation, on the other hand, is novel and useful but gets some value extracted from the ideas. It is more about refining ideas, understanding risks/constraints, avoiding problems and understanding the users. Innovation is implementing something new or original.

"Creativity is not Innovation, but all Creative Things are Innovative". Innovation is considered as a subset of creativity, which induces more iterative, articulated and manifested processes.

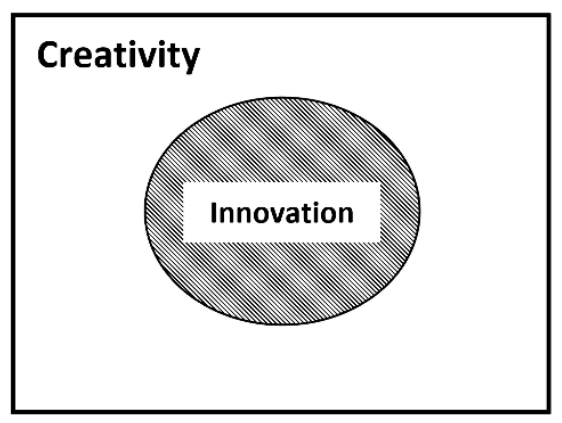

Fig. 1. Difference between Creativity and Innovation

\section{A. The gap between Creativity and Innovation}

The gap between creativity and innovation can be filled by critical thinking which is all about asking the right questions, questions which helps one assess both the meanings and significance of claims \& arguments.

Critical thinking comprehends many important skills such as problem-solving, analysis, interpretation, evaluation and reasoning.

According to Forbes, though $70 \%$ of university graduates are believed to have critical thinking abilities to succeed in their professions, only one-third of employers agree. Hence new approaches to education and recruitment are needed to address this "gap".

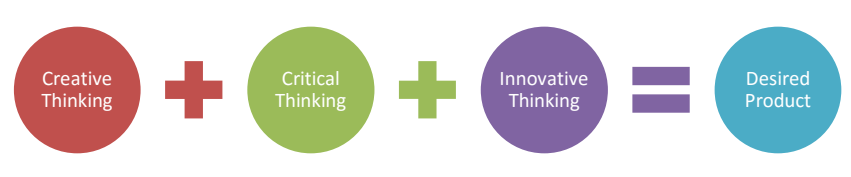

Fig. 2. Collaborative Thinking

\section{Barriers to Innovation}

\section{A. Motivation}

Often Learners are demotivated by putting forward questions "Why Change?" and "What to Change?" which makes them fall in the pit of puzzles. Motivation is the success of empowerment. People aren't being motivated to innovate. Most academics are finely tuned towards the conventional and traditional methodologies. Instead of encouraging and empowering people, often, they are discouraged and put in the panorama of fear of failure.

\section{B. Diversity}

Lack of diversity has also been considered as one of the critical challenges encountered. Most of the time people stop after reaching a particular stage, discontinuing their project due to lack of awareness, knowledge, and resource in the respective field. It is indeed a great factor if there are multidisciplinary people working together with a common objective [15]. By integrating and transfusing various disciplines and cultures into one, more effective and efficient works could be obtained.

\section{Resource}

Innovation extensively requires various resources and support from various sectors. It is incomplete to form ideas and conceptualize but, not bring it into reality. Even resource persons who play a crucial role in defining the design process are very important. All the departments and management should empower the learners to go ahead in their innovative projects.

D. Strategy

Often, many organizations have understood the importance of innovation, but have failed to execute their projects due to 
a lack of strategy. Merely providing resources and empowering learners are not sufficient. There has to be thorough research, recognizing the true needs, before framing skill development programs. The design thinking process shall be imbibed among the learners, strategically at regular periods to get the best out of them.

\section{E. Decentralization}

Innovation has been considered as a primary responsibility of a few particular functional groups like the department of design, research and development, entrepreneurship cell, etc. It is important to decentralize this myth that innovation is dealt by these departments alone. Every department has its own unique flavor and brings a different perception to users contributing to successful innovation.

\section{F. Collaboration}

Collaboration is a prerequisite for innovation. Collaborating internally has been reached out to many, but still, there is an equivalent importance of collaborating externally. Industries play a vital role, and the industry-institute partnership has proved to be fruitful in driving innovations. Collaborating with various industries, customers, competitors and more, cultivates an innovative ecosystem that boosts innovation by practicing forward-thinking.

\section{G. Assessment}

Assessment makes an important role in improving innovations. It is highly important to set certain benchmarks that are strategic but are not simply statistical in nature. One needs to understand how to pervade innovation culture in an organization, by measuring innovations which are marked approximately by scaling them with respect to the number of ideas generated, the amount of time spent on innovation, the investment put on innovation, etc., rather than sales, revenue, bargaining capacity, and relevant statistical metrics.

\section{Role of Technology in Education}

Earlier, many debates occurred on the topic of technology and education, providing many positive and negative feeds over time. Many have perceptions to modernize education by aiding it with the technology. Over a period of time, technology had started to become a very crucial part of the education system. With a proper vision and reason, technology and education are proven to be of great conflation.

Is technology improving our education to a greater extent? It is obvious that technology has become a necessary tool for transforming education in a better form.

Few ways where technology provides a better scope for education can be showcased as-

- A common platform to collaborate and share their ideas.

- A wide spectrum of resources available online.

- Ways to develop one's skills at a younger age.

- Effective time management by flipping classroom.
- Computer managed learning, providing appropriate and adept materials for learning.

- Systematic research and review using various tools.

- Availability of new learning models and cognitive learning.

Few technology programs that are in light -

- GOOGLE'S CHROME BOOK - They are relatively cheap, intellectual, easy to manage, provides a wide range of access to resources.

- DREAMBOX, STMath - Software programs for math which adapt according to students as they learn.

- ACHIEVE 3000, NEWSELA - Programs that help the area of arts by providing students with effective ways to understand reading and writing easily.

- QUIZLET - A software program that helps instructors to manage and test their learners in the classroom.

- GOOGLE FORMS - Provides instructor, researcher, educators with a wide variety of options in order to conduct surveys, feedbacks, examinations, etc.

- LUCID CHARTS - A program that helps in conceptualizing by mapping the whole process and planning in accordance with the design process in order to achieve the objective etc.

- OPENTAX - It is an open education resource, where plenty of Information Materials, papers, articles are available for free.

- GOOGLE CARDBOARD - Using these soft wares, students/instructors can create 3D Videos and watch them simulate into the physical environment.

- PIAZZA - A discussion forum that brings collaborative learning.

- RAPID PROTOTYPING TOOLS - 3D Printers, 3D Pens and many bringing the ideas from Virtual Space to Reality.

\section{Students Perspectives}

A random feedback was collected from various groups of Civil Engineering Students in order to understand and analyze their views on engineering education

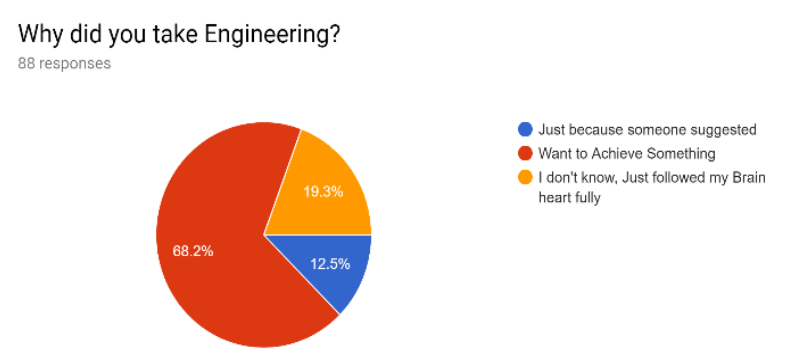




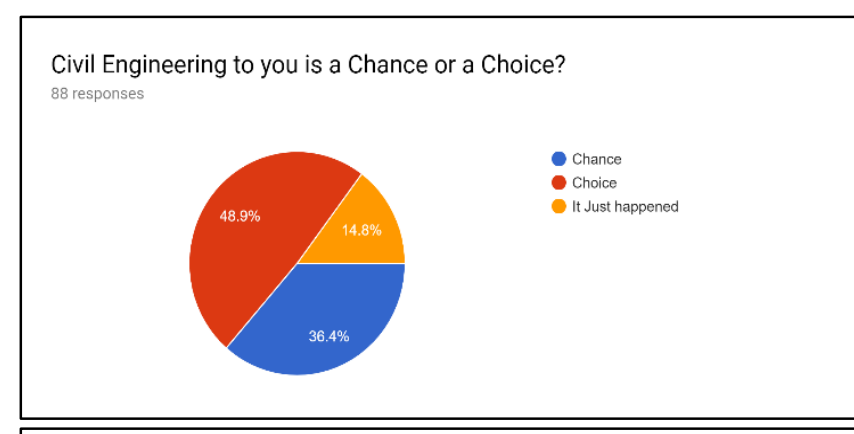

How is Our Present Education System, in terms of Teaching and Learning? 88 responses

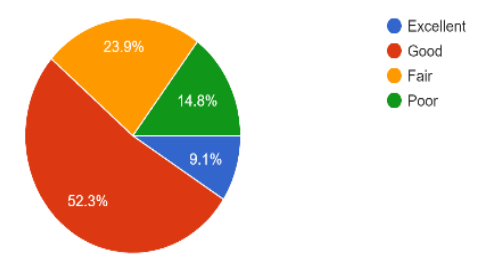

What do you think is more important in life? 88 responses

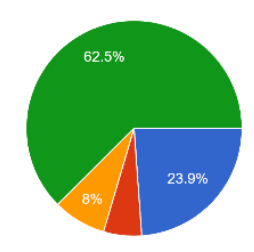

\section{- Critical thinking} Unorthodox thiking - Probably All

According to You, how would you like the classes to be? 88 responses

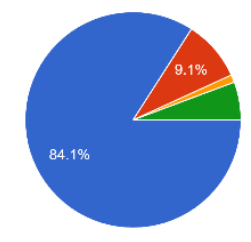

- Creative Learning

Only Technical Teaching

Dictating Notes

(n)

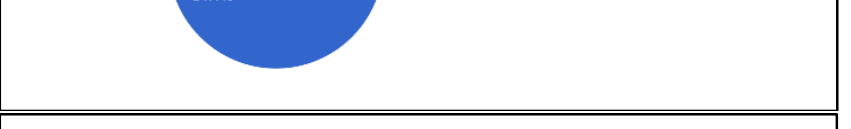

With the Present scenario, where would you see yourself after Five Years? 88 responses
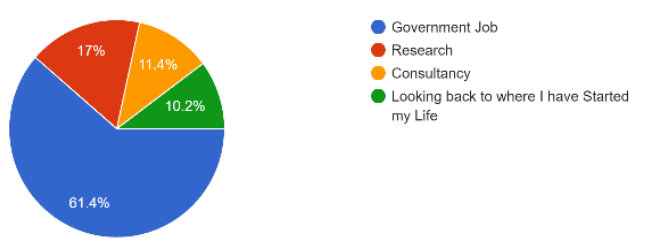

\section{Strategies and Discussions}

From the above feedbacks considered, it was clearly observed that the majority of the students lack vision and are in a state of unclear mind. Only $17 \%$ showed intentions towards research and only $9.1 \%$ accorded our present education system to be excellent. It was indeed significant to see $84.1 \%$ would love to have creative learning classes rather than just traditional.

In order to improve the learning strategy and counter challenges, many approaches and techniques are adopted. For practical and industrial awareness various industry collaborations, incubation centers, workshops, technical conferences, industrial visits and many more were put forth. It also provided various employment and internship opportunity to train in the real world. Sustainability played a crucial role where students were exposed to different aspects. We started making our labs and workspaces more and more sustainable where learning practices were done on reusable wastes rather than producing wastes.

In order to nurture creativity in the young engineers various teaching methodologies such as active learning techniques, collaborative learning, role play, analogy, simulations and presentations, quiz, webinars, video lectures, brainstorming, pain storming, problem-solving, design process methods and many more which inculcate the interest in leaning were promoted. To bring hands-on experience, many programs such as Introduction to engineering, Product design studio, Foundation to product design, EPICS were introduced, which were generally funded by agencies or institutions. These courses brought an interdisciplinary approach which integrated young minds to share and acquire knowledge to a greater extent.

\section{Conclusion}

The importance of harmonizing learners with real-world and practical engineering design methods using Technology and its applications while developing their course projects has been discussed thoroughly. Also, the need for understanding and learning engineering fundamentals has been communicated in this paper. The essential challenges educators are facing to deliver have been clearly elucidated. Various approaches have been adopted to bring sustainable change in transforming engineering education by effectively utilizing tools and technology available in accordance with efficient pedagogies.

\section{References}

[1] The Secretary's Commission on Achieving Necessary Skills (SCANS), US Department of Labor, "What Work Requires of Schools: A SCANS Report for America 2000," June, 1991.

[2] Wingspread Group on Higher Education, "An American Imperative: Higher Expectations for Higher Education," 1993, The Johnson Foundation, Inc., Racine, WI.

[3] Engineering Deans Council and Corporate Roundtable of the American Society for Engineering Education (ASEE), "Engineering Education for a Changing World," October, 1993, ASEE. 
[4] Sumithra Devi K.A, Andhe Dharani, Vijayalakshmi M.N, "Transformation in Engineering Education: An Analysis of Challenges and Learning Outcomes", Recent Advances in Education and Educational Technology, ISBN: 978-1-61804-300-9

[5] Engineering Deans Council and Corporate Roundtable of the American Society for Engineering Education (ASEE), "Engineering Education for a Changing World," October, 1993, ASEE

[6] "Industrial Engineering Education and Research: Current Issues and Future Directions for the Caribbean" Colin O. Benjamin, Leslie Monplaisir, Clement K. Sankat and Denise Thompson, The Journal of the Association of Professional Engineers of Trinidad and Tobago Vol.37, No.1, October 2008, pp.4-16, ISSN 10007924

[7] "Communication Skills for the 21st Century Engineer", Marc J. Riemer, UNESCO International Centre for Engineering Education (UICEE), Global J. of Engng. Educ., Vol.11, No.1

[8]http://timesofindia.indiatimes.com/articleshow/5769813 3.cms?utm_source $=$ contentofinterest\&utm_medium $=$ text $\&$ utm_campaign $=$ cppst

[9] "ETHICAL ISSUES AWARENESS FOR ENGINEERS IN PRACTICE", Dr. A. Dean Fontenot, Texas Tech University, Mr. Richard A. Burgess, National Institute for Engineering Ethics, American Society for Engineering Education, 2012, AC 2012-5438

[10] National Academy of Engineering, The Engineer of 2020: Visions of Engineering in the New Century, Washington, DC: National Academies Press (2004).

[11]https://timesofindia.indiatimes.com/home/education/ne ws/Importance-of-general-

awareness/articleshow/1023322313.cms

[12] O. Rompelman and E. De Graaff, "The Engineering of Engineering Education: Curriculum Development from a Designer's Point of View," European Journal of Engineering Education, Vol. 31, No. 2, 2006, pp. 215-226.

[13] Alok, G., Anushalini, T., \& Condoor, S. (2018). Effective Approach towards Development of Idea through Foundations to Product Design. Journal of Engineering Education Transformations, 31(3), 47-52.

[14] Alok, G., Pothupogu, S., Reddy, M. S., \& SaiPriya, P. (2018, November). Trenchant Pathway to bring Innovation through Foundations to Product Design in Engineering Education. In 2018 IEEE 6th International Conference on MOOCs, Innovation and Technology in Education (MITE) (pp. 43-47). IEEE.
[15] Kumar, K. S., Alok, G., Reddy, M. S., \& Reddy, N. C. S. (2018, November). An integrated Multidisciplinary skill development strategy for effective execution from virtuality to reality in Engineering Education. In 2018 IEEE 6th International Conference on MOOCs, Innovation and Technology in Education (MITE) (pp. 79-83). IEEE.

[16] Jetti Rahul, Pothupogu Soumya, Govil Alok (2018), “A Smart and Sustainable Approach For Planning A Trenchant Green City", International Journal of Civil Engineering and Technology, Volume 9, Issue 13, December 2018, pp. 705711, ISSN Print: 0976-6308 and ISSN Online: 0976-6316 